\title{
Building From the Ground Up: The Key to Health and Well-Being in Schools
}

Sharon Klein

\begin{abstract}
In this interview, Sharon Klein, the Head of School at St. George's School of Montreal, discusses how health and well-being are integrated in the curriculum and school life. Since its beginning in 1930, St. George's has operated on six founding principles, the first of which is "health comes first." Ms. Klein describes how this principle is being applied-yoga, mindfulness, exercise literacy-and further describes how they have developed the Core 5 Program, based on current research, to meet the needs of today's students. She concludes by sharing her vision of health and well-being in the future.
\end{abstract}

You've been here a few years now and I was wondering if you could give us a bit of the history of St. George's and talk about the founding principles of this school?

Principles are what we embody today. We have been teaching 21 st century skills since 1930. Our Founding Principles encompass not only the academic piece of teaching to the individual child, but also the social/emotional piece, working in groups, collaboration, creativity, and critical thinking. All of the things that we think are good teaching practices today are really what we were founded on. I feel fortunate to be here because I feel like that's been ingrained in this school and embedded since 1930. It's really what every good school is striving to be known for now.

With these principles in mind, can you describe how St. George's focuses on health and well-being? For example, what's done in elementary school / what's done in high school?

Health and well-being has many different facets to it. One of the facets is promoted through our physical education classes. In our elementary school specifically, we refer to physical education as "physical literacy." There is a big push from our physical education [staff] there to really educate the children about the body and the mind, and how they work together. They are well versed with technology and they use it in their classes to analyze each child's movements in order to help them understand how they move, and how important movement is to their health. Our teachers are really focusing on physical literacy as a way of life, as opposed to a "just getting in the gym and playing" approach. And that's just a small snapshot of what goes on in the elementary.

An important piece of promoting health and well-being that runs through the elementary and the high school is what we call our "Core Five Program," [which is] a social/emotional learning program that is being developed specifically by our teachers for students from kindergarten through grade 11 . We have a research and design committee (CLE: Centre for Learning Enrichment) that decides how this process is implemented. They've been working on the Core Five for three years-which includes a focus on 
interpersonal skills, intrapersonal, perseverance, realistic optimism, and leadership-i.e., how do we live these things on a day-to-day basis. The beauty of this program is that it's been designed by the teachers, so it's something that we're very gradually moving forward, and importantly, we are embedding it into the fabric of our culture. The students are involved in this process as well, giving feedback as we continually move forward.

In the high school, of course, we also have this fantastic new fitness centre, which is not just used for coming and working out physically, but we've also got a big floor area here that you can use to do mindfulness activities, yoga, or dance-or whatever a student feels is appropriate for their needs. As part of our Core Five Program, the teachers could come in and use this in different ways as well. The kids are loving it, of course. The physical aspect of coming and working out includes intentional goal setting, which is an important piece of introducing this new facility to our students. The students have been involved in setting their own goals and ensuring that when they come in they're actually working towards a purpose. The curricular piece is really important-it's not just a facility that was built and "there you go." There's been a lot of thought put into how it works within our whole curriculum and how it integrates throughout.

What roles do the students play in supporting health and well-being principles?

Obviously, they're involved in many extracurricular and many different activities throughout the year and these activities allow them to stretch themselves and build confidence. This confidence allows them to feel comfortable taking on leadership roles. For example, we brought in a certified personal trainer and have provided older students who are interested with the opportunity to learn from them and receive training certification, with the goal that our older students can help and work with our younger students. We are giving them an opportunity to take on a leadership role in this area, and that's a program we hope to continue to expand in the future. We've just begun because the centre has only been open for a month now. But that is one of the current ways we see students more involved in leadership opportunities. I can see that in the future there could also be a leadership role that high school students would play in mentoring our younger students (elementary school) with regard to health and wellness. In relation to our Core Five Program, our students give feedback on curricular lessons, our Zen Lunch Hours, our cafeteria food choices, and many other health initiatives. The student voice is an important one in our community. In the upcoming year, we intend to focus more on this guiding principle, "health comes first," and our students will be very involved in setting the direction as to where we will go with that theme. It is important to us as a school to collaborate with our students, and they never cease to amaze us with their creative ideas and well-articulated thoughts. 
Since the inception of the school, parents have been involved in St. George's and actually run the school in a sense. How do they support health and well-being principles?

You're right: we definitely partner with our parents. I think that's something that's unique about St. George's. Our Board is mostly made up of parents and they have to be a current parent to be a voting member and be the Chair of the Board. They've been involved in many ways since before I came to this school. I know they were involved in a food committee previously, and one of our Board Members who is a physician was instrumental in that initiative. We have board members with different roles and also other parents from the community that act on committees. They look at nutrition within the school with a critical eye. Our Buildings \& Grounds Board Chair was integral in developing the overall building plans for our fitness centre. We keep our parents very informed as to how we're working with the students. We have parent breakfast meetings...the adults will come in...they'll give us feedback on what their children are saying or doing or feeling. For example, we held a parent breakfast meeting that focused on the process of how the students would be introduced to the fitness centre-this involved goal setting, and training sessions on use of equipment and facilities. One of our parents was very involved in training our student supervisors. At St. George's the adults are very much involved, depending on what comes up in any area of health or wellness. We also have parents whose work involves teaching Mindfulness and they have been great resources, as well as offering workshops for faculty and staff. We've brought parents in to teach a yoga class. So, as you can see, they are very much aware of what's happening in this school and I really feel that they enjoy being a part of health and wellness initiatives. It truly is a partnership and it is important to us that our parents have a voice. I appreciate their support.

What is your vision for health and wellness in the future?

My vision would be that every single student within our school-and not even just the students, but the alumni, all the community members - that it is something that is really integrated into their lives. Whether we're talking about being physically active or whether it's something involving your mental health (as I said, the social-emotional piece), that it is something that is taught in every school, not just our school, but in every school it is being practiced and being integrated because we know that in order for students to do well academically, as well as emotionally, health and wellness has to be an integral part of the curriculum.

At our school, one of the things that we're looking forward to is an upcoming building project-we're hoping to build a wellness centre which could be a flexible and dynamic space that could be used for any of those-either psychological or physical well-being. It would be very flexible and it could also be used for community gatherings. It would be a space that would allow our wellness curriculum to grow. 
What suggestions do you have for other school leaders who are seeking to promote health and wellbeing of both students and staff in their schools?

The main suggestion I would have is to embed it in the curriculum. I think that anything you do, if it's really important it can't be just an add-on and you can't leave to chance whether it happens or not. It has to be something that is built from the ground up. You really need to have students involved, and consider carefully what that will look like. You need to have parents involved; you need to have your staff and faculty involved as well. If it's built together and it's something that can be embedded in your curriculum, then it's going to happen. People are going to see it as something that's really important, and it's going to be there for many years to come.

Our founding principle is "health comes first" and it is so true. Health has so many different facets to it. I really think that we should be attending to it as schools. As leaders, we need to role-model it and, once again, we really need to build it from the ground up so that it is embedded in all our schools.

Can you get into some of the details of what Core Five is?

Our research and design team, which is led by our Assistant Heads of Curriculum...this team looks at how we should be moving forward as a school, what does the research say, what kind of professional development do our teachers need, and, what's the next step to take us forward? Before I came to this school, a couple of years before, that group looked at what's happening in the research. And definitely we're seeing a lot more anxiety in schools; we're seeing children that are having more difficulty and more stress. So, they looked at what type of program could we create within the school that would really be something that would help our students. They came up with what's called the "Core Five" - core meaning it's the core of the person and "five" meaning it's focusing on five different areas. So far, we've only developed four. For example, the first one is all about yourself as a person: "intrapersonal." From kindergarten to grade eleven they would discuss that core, but, of course, it would be a progression of learning throughout as to what they might discuss. The second core is "interpersonal" - the interpersonal piece being how I am in relationship with relating to somebody else. The third core is all about perseverance and persistence and the importance of that. The fourth one is about realistic optimism. How can we be realistic, but still optimistic? How we can instill that growth mindset? The fifth core hasn't been developed yet, but what we're thinking about is how we action these other four coresand that, we believe, is the leadership piece. The teachers have worked in teams and have currently designed three of four lessons and each are appropriate for the age and grade they teach. By having our teachers create these lessons over time, they have internalized them, and can then apply them in every aspect of school life. 


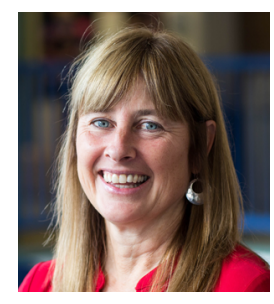

Sharon Klein is a lifelong learner who is passionate about the educational experience at St. George's School of Montreal. As Head of School, she is an advocate for progressive and research-based education. She is widely respected as a collaborative leader and is dedicated to the St. George's individualized approach to teaching and learning. In alignment with the School's mission and vision, Sharon is spearheading a school-wide sustainability initiative that calls faculty, staff, and students to be engaged and responsible citizens of the Earth, and to model a fully sustainable environment within the school. She is also dedicated to fostering the continued growth of the School's Centre for Learning Enrichment into a preeminent resource for best practices in learning. 